\title{
CARACTERIZAÇÃO MICROPEDOLÓGICA DE SOLOS REABILITADOS APÓS EXPLORAÇÃO DE BAUXITA EM PORTO TROMBETAS (PA) ${ }^{(1)}$
}

\author{
M. L. P. RUIVO(2), C. E. G. R. SCHAEFER ${ }^{(3)}$, N. F. BARROS ${ }^{(3)}$, \\ M. A. ALBUQUERQUE ${ }^{(4)} \&$ L. M. RIBEIRO(5)
}

\begin{abstract}
RESUMO
Foi realizado um estudo micromorfológico em solos alterados após a exploração de bauxita, em sítios recuperados entre 1981 e 1987, em comparação ao Latossolo Amarelo inalterado (LA), como referência, para subsidiar indicadores de recuperação dos solos. O estudo foi desenvol vido no Platô Saracá, na mina de bauxita de Porto Trombetas, município de Oriximi ná, no estado do Pará. Técnicas micromorfológicas e uso de microssonda de EDS, microscopia ótica e eletrônica de varredura foram avaliadas em conjunto com dados físicos e químicos dos solos alterados e do LA, nas profundidades de 0-10 e $40-50 \mathrm{~cm}$. 0 Latossolo Amarelo mostrou forte microestrutura granular, enquanto os solos alterados apresentaram grande variabilidade em microestrutura e feições micropedológicas. O retorno do horizonte superficial, rico em matéria orgânica, favoreceu a microagregação. De modo geral, os solos alterados mostraram maior massividade e agregados mais coalescidos, em relação ao LA de referência. Análises microquímicas de EDS comprovaram a heterogeneidade dos solos superficiais alterados, com ocorrência de nódulos gibbsíticos, ferruginosos, concreções, agregados cauliníticos e plasma dominado por argilominerais 1:1, sob intensa pedobioturbação.
\end{abstract}

Termos de indexação: Latossolos, solos alterados, micromorfologia, indicadores de recuperação, Amazônia.

\footnotetext{
(1) Parte integrante da Tese de Doutorado do primeiro autor, apresentada ao curso de Pós-Graduação em Sol os e Nutrição de Plantas da Universidade Federal deViçosa - UFV. Apoio Financeiro CMRN, CAPES e CNPq. Recebido para publicação em março de 2001 e aprovado em fevereiro de 2002.

(2) Pesquisador, Coordenadoria de Ecologia/Museu Paraense Emílio Goeldi. Av. Perimetral 1901, Caixa Postal 399, CEP 66040-170 Belem (PA). E-mail: ruivo@museu-goeldi,br

(3) Professor do Departamento de Solos, Universidade Federal de Viçosa - UFV. CEP 33571-000 Viçosa (MG). Bolsista do CNPq. E-mail: nfbarros@mail.ufv.br

(4) Professora do Centro de Pesquisas, FUNEC. Av. Moacir de Mattos 49, CEP 35300-040 Caratinga (MG).

(5) Engenheiro-Agronômo, UNIMONTES, J anaúba (MG). Bolsista Apoio Técnico Pesquisa CNPq.
} 


\title{
SUMMARY: MICROPEDOLOGICAL CHARACTERIZATION OF ALTERED SOILS AFTER BAUXITE MINING IN PORTOTROMBETAS (PA)
}

\begin{abstract}
A micropedol ogical study was carried out in rehabilitated soils after bauxite mining, in sites dating from 1981 to 1987, compared with theYel low Latosol, as reference, to subsidize soil indicators of rehabilitation. The study was located in Porto Trombetas, district of Oriximiná, northwestern Pará State. Micromorphol ogical techniques, using EDS/ SEM microprobe, optical and scanning electronic microscopy, were used in combination with chemical and physical analysis, at 0-10 and $40-50 \mathrm{~cm}$ depths. The Yell ow Latosol showed a strong devel opment of mi crogranul ar structure, whereas theal tered soils presented a great variability with respect to microstructure and micropedological features. The spread of topsoil back onto thesites, due to organic matter richness, favored the surfaceaggregation. Overall, the altered soils were more massive and with coalesced peds, compared with the Yellow Latosol. SEM/EDS Microchemical analysis have confirmed the heterogeneity of surface altered soils, with occurrence of gibbsite and ferruginous nodules, caulinitic aggregates and soil plasma of 1:1 clay composition, under intense pedobioturbation.
\end{abstract}

Index terms: Latosols; mi cromorphol ogy, altered soils, indicators of rehabilitation; Amazonia.

\section{NTRODUÇÃO}

O município de Porto Trombetas está situado à margem direita do rio Trombetas, no município de Oriximiná (PA), onde ocorre a exploração de bauxita em platôs de 50-150 m de altitude.

Na Amazônia, o platô Saracá, situado no domínio do Planalto Dissecado Rio Trombetas - Rio Negro (Nascimento, 1976), foi a primeira mina a ser reabilitada após o final da lavra mineral. O solo do platô Saracá foi classificado por Viana (1976) como Latossolo Amarelo álico (LA), originado de rochas sedimentares do Grupo Barreiras, apresentando o horizonteA pouco espesso e o horizonte $\mathrm{B}$ profundo. É um solo muito argiloso, ácido, com altos teores de Al trocável e baixos teores de fósforo, de cálcio e de magnésio (Viana, 1976; Ferraz, 1991; Ruivo, 1991). O perfil típico das áreas mineralizadas em bauxita mostra uma camada superficial de solo com teores médios a altos de carbono orgânico (horizonte A), com espessura média de $15 \mathrm{~cm}$. Abaixo deste, ocorre um horizonte B caulinítico, com aproximadamente $200 \mathrm{~cm}$ de espessura e, sob esse pacote pedogenizado, ocorre depósito argiloso, de cor amarela, caulinítico. $\mathrm{Na}$ base do depósito argiloso, encontra-se bauxita nodular em camada com espessura de até $250 \mathrm{~cm}$, constituída por pisólitos ferruginosos e nódulos de gibbsita em matriz argilosa. A camada subjacente à bauxita nodular éuma laterita ferruginosa (couraça) com espessura máxima de $200 \mathrm{~cm}$. Logo abaixo desta camada, encontra-se uma camada de bauxita compacta com espessura variando de 300 a $600 \mathrm{~cm}$, que constitui o principal minério explorado (Pereira \& Knowles, 1985; Promom, 1988).

Em Porto Trombetas, além da floresta tropical densa, caracterizada por árvores com altura máxima de até $45 \mathrm{~m}$ e diâmetro de até $1 \mathrm{~m}$ (Pereira \& Knowles, 1985), destaca-se a vegetação oriunda do reflorestamento das áreas reabilitadas após a extração da bauxita. Atualmente, após a retirada da bauxita, a área é recomposta com o retorno do horizonte A ("topsoil") do solo original (Latossolo Amarelo argiloso), à exceção dos plantios de 1981, 1986 e 1994 e do plantio de espécies vegetais nativas e exóticas.

A mineração de bauxita modifica o sol o quanto à topografia e circulação de água (Schroeder, 1995), reduzindo a camada orgânica ea disponibilidade de nutrientes (Li \& Daniels, 1994; Ruivo, 1998). Em Porto Trombetas, os sítios reabilitados que datam de 1981 não receberam cobertura do topsoil, rico em matéria orgânica. Entretanto, Ruivo (1991) verificou a presença de bolsões descontínuos de material orgânico em trincheiras abertas no sol o al terado, em alguns sítios reabilitados em 1981. Essa variabilidade acidental decorreu da mistura dos horizontes $\mathrm{B}$ emateriais subjacentes com o material superficial mais rico em matéria orgânica, que ficou na parte superficial do solo alterado durante o espal hamento do material com tratores.

A adição de matéria orgânica, pelo retorno do "topsoil" ou da revegetação, melhora as condições edáficas e o desenvolvimento da vegetação (Ruivo, 1991; Li \& Daniels, 1994; Parrotta et al., 1997). Em Porto Trombetas, Ruivo (1998) verificou que as condições edáficas e o efeito das espécies vegetais foram mais atuantes no desenvolvimento da vegetação que o efeito temporal e que o retorno do horizonte $\mathrm{A}$ pedogenético e o restabel ecimento da cobertura vegetal aceleraram a recomposição edáfica dos sítios alterados pel o favorecimento ao acúmulo de resíduos vegetais e a atividade biológica.

Os estudos em solos indeformados em escalas microscópicas podem mostrar algumas destas modificações, fornecendo informações sobre o material de origem e variações físicas, químicas e 
biológicas. Estudos micromorfológicos de solos têm evidenciado a importância da atividade biológica (Nunes at al., 2000; Oliveira et al., 2000; Schaefer, 2001), a forma dos poros e a compactação das camadas (Faria, 1996), permitindo avaliar a evolução dos processos de alteração desenvol vidos a partir de material de origem de composição geoquímica distinta (Lacerda et al., 2000).

No presente trabalho, avaliou-se e comparou-se a micromorfologia dos solos alterados após a recuperação paisagística em diferentes anos com as feições micropedológicas, químicas e físicas do Latossolo Amarel o de referência.

\section{MATERIAL E MÉTODOS}

\section{Descrição dos sítios amostrados}

O sítio de referência do Latossolo Amarelo (LA) está situado no centro do platô Saracá. A cobertura de mata primária foi parcialmente alterada pela entrada de tratores e pela retirada de sementes e de indivíduos de maior porte e de interesse econômico. Trata-se de um Latossolo Amarelo argiloso álico horizonte $A$ moderado pouco espesso e horizonte $B$ profundo.

Nos solos alterados, foram estudados sítios localizados na borda, onde não houve retorno do topsoil (sítios 1, 2, 3 e 4-reabilitados em 1981) e, no centro do platô, ondehouve retorno do topsoil (sítiol0 reabilitado em 1984 com Terminal ia catappa esítio 12, reabilitado em 1987). Nos primeiros, o solo é mais compactado, a espessura da camada orgânica é mais delgada e apresenta baixa disponibilidade de nutrientes, dificultando o desenvolvimento da vegetação replantada. Nos sítios 10 e 12, local izados no centro do platô, graças ao retorno do topsoil, o solo alterado apresenta maior disponibilidade de nutrientes com mel hor agregação e camada orgânica mais espessa, em relação à borda e ao LA de referência, favorecendo o melhor desenvolvimento da vegetação ali implantada.

\section{Análises micromorfológicas}

Coletaram-se amostras para análises micromorfológicas, físicas e químicas nas profundidades de 0 10 ede $40-50 \mathrm{~cm}$. Para as análises mi cromorfológicas, amostras indeformadas de solo foram col etadas em caixas de Kubiena, sendo, posteriormente, impregnadas com resina e confeccionadas lâminas polidas (seções-finas) nas dimensões de $3 \times 6 \mathrm{~cm}$, analisadas em microscópio petrográfico. As lâminas foram descritas, conforme as recomendações de Fitzpatrick (1993), dando-seênfaseà microestrutura, observações sobre feições micropedológicas e atividade biológica. As características físicas e químicas do sol o foram anal isadas segundo métodos preconizados por EMBRAPA (1997).

\section{Microanálises em seções finas}

Seções finas selecionadas, previamenteestudadas em microscópio petrográfico com polimento manual, foram preparadas para microanálise em mi croscopia eletrônica de varredura. Amostras de 2,0 x 2,5 cm foram pol idas sucessivamente em disco de nylon com pasta de diamante, desde60,6, 3 até $1 \mu$. Após lavagem ultra-sônica final para remoção de resíduos do pol imento, as seções finas foram recobertas com filme condutor de carbono emontadas em suportemetálico.

As lâminas foram subseqüentemente anal isadas e fotografadas em mi croscópio el etrônico de varredura, model o J EOL J SM 6400, com detector backscattering e acoplado a espectrômetro de dispersão de raios-X (PCXA-EDS) para exame mi croquímico das feições sel ecionadas. As análises microquímicas foram efetuadas com voltagem de $15 \mathrm{kV}, 5 \mathrm{~A}$ e a $39 \mathrm{~mm}$ de distância de trabalho (detector-superfície). A cada troca de amostras, o PCXA-EDS foi recalibrado com padrão de cobre.

Foi elaborado um menu de elementos para analise quantitativa em EDS. Foram obtidos mapas microquímicos das áreas selecionadas, para os principais elementos presentes ( $\mathrm{Si}, \mathrm{Al}, \mathrm{FeeTi}$ ) e, após a identificação de feições pedológicas com características químicas distintas, procedeu-se à análise dessas feições em magnificação elevada, obtendo-se espectros quantitativos deEDS, gravados em computador. Todas as feições foram analisadas em três repetições, mapeadas e fotografadas em imagens de retroespalhamento de elétrons (backscattering) para visual ização da sua morfol ogia.

\section{RESULTADOS E DISCUSSÃO}

Com base nas observações micropedológicas de amostras col etadas em alguns sítios estudados, elaborou-seo quadro 1, que contém informações sobre al gumas características físicas equímicas sel ecionadas e uma descrição micromorfológica sucinta do solo, nas profundidades de $0-10$ e de $40-50 \mathrm{~cm}$.

No solo inalterado, observou-se uma microestrutura composta, com blocos subangulares pequenos + granular típica, com tendência de predomínio de microagregados subesféricos na faixa de 0,3-0,5 mm (Figura 1a), entremeados por microagregados muito pequenos, menores que $0,06 \mathrm{~mm}$, com limites difusos, aderidos em graus variados à superfície dos agregados maiores. O caráter difuso e pouco definido dos microagregados pequenos parece estar relacionado com a presença de argila dispersa em água na profundidade de $0-10 \mathrm{~cm}$, o que é corroborado pelo grau de floculação (GF) de $93 \%$ (Quadro 1). O aumento da argila dispersa na superfície, por sua vez, parece depender dos valores mais elevados de carbono orgânico (CO) nesta profundidade, causando dispersão. 
Quadro 1. Características físicas, químicas e micromorfológicas dos solos de sítios em recuperação (1, 2, $3,4,10$ e 12) e do solo inalterado (LA), usado como referência no presente estudo

\begin{tabular}{|c|c|c|c|c|c|c|c|c|c|c|}
\hline Sítio & Prof. & Areia & Silte & Argila & GF & Microestrutura & $\begin{array}{c}\text { Feições } \\
\text { Micropedológicas }\end{array}$ & CO & $\begin{array}{c}\mathrm{pH} \\
\mathrm{H}_{2} \mathrm{O} / \mathrm{KCl}\end{array}$ & Atividade biológica \\
\hline & $\mathrm{cm}$ & 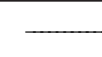 & $-\mathrm{g} \mathrm{kg}^{-1}$ & - & $\%$ & & & $\mathrm{~g} \mathrm{~kg}^{-1}$ & & \\
\hline \multirow[t]{2}{*}{$\begin{array}{l}\mathrm{LA} \\
\text { (ref.) }\end{array}$} & 10 & 67 & 108 & 824 & 93 & $\begin{array}{l}\text { composta, blocos } \\
\text { subangulares } \\
\text { pequenos }\end{array}$ & $\begin{array}{l}\text { fragmentos carvão, } \\
\text { restos orgânicos } \\
\text { lignificados }\end{array}$ & 36,3 & $3,8 / 3,5$ & $\begin{array}{l}\text { intensa atividade } \\
\text { biológica }\end{array}$ \\
\hline & 50 & 51 & 24 & 925 & 100 & $\begin{array}{l}\text { microgranular } \\
\text { (idem } 50 \mathrm{~cm} \text { ) }\end{array}$ & $\begin{array}{c}\text { idem, c/nódul os em } \\
50 \mathrm{~cm}\end{array}$ & 13,1 & $4,2 / 4,2$ & raros canais \\
\hline \multirow{2}{*}{$\begin{array}{c}1 \\
(1981) \\
\text { borda }\end{array}$} & 10 & 54 & 122 & 789 & 100 & $\begin{array}{c}\text { composta massiva } \\
+ \text { blocos } \\
\text { subangulares }\end{array}$ & $\begin{array}{c}\text { raros frag. } \\
\text { lignificados, carvão, } \\
\text { conc. bauxita }\end{array}$ & 10,8 & $4,2 / 4,4$ & $\begin{array}{l}\text { canais biológicos e } \\
\text { pel otas fecais }\end{array}$ \\
\hline & 50 & 65 & 107 & 803 & 100 & $\begin{array}{l}\text { composta massiva } \\
\text { + granular + blocos } \\
\text { subangulares }\end{array}$ & $\begin{array}{l}\text { laterita e nódulos } \\
\text { macios idem } 50 \mathrm{~cm}\end{array}$ & 19,3 & $4,4 / 4,2$ & raros canais \\
\hline \multirow{2}{*}{$\begin{array}{c}2 \\
(1981) \\
\text { borda }\end{array}$} & 10 & 66 & 151 & 745 & 100 & $\begin{array}{c}\text { composta massiva } \\
+ \text { blocos } \\
\text { subangulares }\end{array}$ & $\begin{array}{l}\text { abundantes nódulos } \\
\text { e conc. com } \\
\text { recobrimento de Fe }\end{array}$ & 6,9 & $4,4 / 5,1$ & $\begin{array}{l}\text { raros indícios de } \\
\text { atividade Biológica }\end{array}$ \\
\hline & 50 & - & - & - & - & sem lâmina & sem lâmina & - & - & - \\
\hline \multirow{2}{*}{$\begin{array}{c}3 \\
(1981) \\
\text { borda }\end{array}$} & 10 & 49 & 121 & 794 & 100 & $\begin{array}{l}\text { composta massiva } \\
+ \text { granular }\end{array}$ & $\begin{array}{c}\text { frag. orgâ. } \\
\text { lignificados, raros } \\
\text { frag. nodulares, } \\
\text { zonas ferruginizadas }\end{array}$ & 20,8 & $4,0 / 4,2$ & $\begin{array}{c}\text { raros canais } \\
\text { biológicos e pelotas } \\
\text { fecais }\end{array}$ \\
\hline & 50 & 51 & 122 & 792 & 100 & $\begin{array}{l}\text { composta massiva, } \\
\text { granular e blocos } \\
\text { subangulares }\end{array}$ & idem, com carvão & 21,6 & $4,2 / 4,2$ & raros canais \\
\hline \multirow{2}{*}{$\begin{array}{c}4 \\
\text { (1981) } \\
\text { borda }\end{array}$} & 10 & 272 & 141 & 588 & 98 & $\begin{array}{l}\text { composta massiva } \\
\text { + microgranular forte }\end{array}$ & $\begin{array}{c}\text { abundantes restos } \\
\text { vegetais, carvão e } \\
\text { nódulos }\end{array}$ & 26,2 & $4,2 / 4,2$ & $\begin{array}{l}\text { intensa atividade } \\
\text { biológica, canais, } \\
\text { pelotas fecais }\end{array}$ \\
\hline & 50 & 149 & 129 & 768 & 100 & $\begin{array}{l}\text { composta massiva } \\
+ \text { microgranular forte }\end{array}$ & $\begin{array}{l}\text { concr., raros nódulos } \\
\text { e frag. dispersos de } \\
\text { carvão }\end{array}$ & 13,1 & $4,2 / 4,2$ & canais biológicos \\
\hline
\end{tabular}

$\begin{array}{ccccccccccc}\text { 10 } & 10 & 206 & 200 & 572 & 62 & \begin{array}{c}\text { composta blocos } \\ \text { subangulares } \\ \text { +granular }\end{array} & \begin{array}{c}\text { abund. nódulos } \\ \text { bauxíticos., concr, } \\ \text { carvões e rest. } \\ \text { vegetais }\end{array} & 30,9 & 4,8 / 4,6 & \begin{array}{c}\text { canais biológicos }+ \\ \text { pelotas fecais }\end{array} \\ \begin{array}{c}(1984) \\ \text { centro }\end{array} & 50 & 85 & 149 & 720 & 100 & \begin{array}{c}\text { composta massiva } \\ \text { +blocos } \\ \text { subangulares }\end{array} & \begin{array}{c}\text { gra. nódulos later/ } \\ \text { baux. degradados; } \\ \text { raros carvões }\end{array} & 8,5 & 4,6 / 5,3 & \text { raros canais }\end{array}$

\begin{tabular}{|c|c|c|c|c|c|c|c|c|c|c|}
\hline \multirow{2}{*}{$\begin{array}{c}12 \\
\text { (1987) } \\
\text { centro }\end{array}$} & 10 & 54 & 80 & 841 & 97 & $\begin{array}{l}\text { blocos subangulares } \\
+ \text { granular }\end{array}$ & $\begin{array}{c}\text { abund. nódulos } \\
\text { bauxíticos } \\
\text { degradados, carvão, } \\
\text { concreção }\end{array}$ & 22,4 & $4,2 / 4,4$ & $\begin{array}{c}\text { canais biológicos + } \\
\text { pel otas fecais }\end{array}$ \\
\hline & 50 & 67 & 106 & 777 & 100 & $\begin{array}{l}\text { blocos subangulares } \\
+ \text { granular }\end{array}$ & $\begin{array}{l}\text { raros nód. muito } \\
\text { pequenos }\end{array}$ & 5,4 & $4,8 / 5,5$ & canais biológicos \\
\hline
\end{tabular}


Embora a matéria orgânica, especialmente os ácidos húmi cos, seja normalmenteconsiderada agente agregante das partícul as dosolo (Martins et al., 1989), certos compostos orgânicos presentes na fração humificada podem atuar como agentes dispersantes (Visser \& Caillier, 1988; Goldberg et al.,1990).

O predomínio de agregados com tamanho entre 0,3 e $0,5 \mathrm{~mm}$ deve estar associado aos valores elevados de CO na profundidade de $0-10 \mathrm{~cm}$ (Quadro 1). O Latossol oAmarel o(LA) inalterado, na profundidade de $0-10 \mathrm{~cm}$, foi o que apresentou os maiores agregados, bem como os mai ores valores de CO. A distribuição do $\mathrm{C}$ em classes de agregados atéà profundidade de $20 \mathrm{~cm}$ (Ruivo\& Schaefer, 1998) também mostra que os teores desse elemento nos macroagregados (0,25 a $2 \mathrm{~mm}$ ) foram maiores no $L A$.

Por ser um solo caulinítico, a microagregação do LA deve ser mais determinada pelo CO que pela mineralogia, fato que reforça a importância da manutenção de teores mais elevados de MO para propiciar microestrutura favorável e boas condições para a recuperação da vegetação.

No solo inalteradoa $40-50 \mathrm{~cm}$, com microagregação semel hante, observou-se menor empacotamento dos agregados pequenos (Figura 1b), o que revel a menor dispersão de argila, associado com menores teores deCO (Quadro 1). O fenômeno de di sper são nos LAs é favorecido pela maior distância do $\mathrm{pH}$ do solo em relação ao pH no ponto de carga zero (PCZ).

$\mathrm{Na}$ profundidade de $40-50 \mathrm{~cm}$, o $\mathrm{pH}$ é maior que a 0-10 cm (Quadro 1), o que indica maior grau de floculação(defato, o GF é 100 \% nesta profundidade). De maneira geral, o sol o inal terado apresentou boas características microestruturais e bom arranjo e distribuição de poros, que deve corresponder às condições esperadas de LAs em ambiente natural .

De maneira geral, os sol os dos sítios reabilitados da borda do platôapresentaram grande variabilidade em microestrutura efeições micropedológicas, de difícil associação com as características físicas e químicas destacadas, tais como: textura, teor de carbono e pH .

Nosítio 1, por exemplo, observaram-seabundância de concr eções bauxíticas na superfície (Figura lc,d), irregularmentedistribuídas na matriz, demicroestrutura massiva e blocos subangulares, onde a microagregação original pareceter sido parcialmente perdida pelo reempacotamento do solo sob o peso das máquinas, e mistura heterogênea da matriz do antigo horizonte $A$ microestruturado (Figura $1 c$ ), com nódul os e concreções lateríticas. A formação de linhas de fraqueza ea geração de estrutura em bloco devem ter ocorrido em virtude de flutuações de umedecimento e secagem desde 1981, sendo notável certa migração de Fe em direção à parede dos poros (F igura le), indicando processo pedogenético.

No sítio 2, foram observadas a mesma tendência à coalescência de microagregados e a formação de microestrutura massiva. Nesta, os microagregados só foram visíveis onde houve precipitação do Fe ao longo das antigas zonas de contato interagregado (Figura 1f), processo que ocorreu no tempo decorrido desde 1981, evidenciando que a massi vidadecausada pelo reempacotamento dos poros causou certa redução e mobilidade de $\mathrm{Fe}$, que migrou dos fragmentos concrecionários e bauxita para as zonas externas, formando novos precipitados na superfície de grãos de quartzo (Figura $1 \mathrm{~g}$ ) ou antigos microagregados coalescidos (Figura 1f). Em alguns casos, houve até mesmo um concrecionamento incipiente e cimentação destes materiais, o que demonstra a rapidez dos processos de oxirredução nesses sol os, quando sujeitos à perda de por osidade.

No sítio 3, também recuperado em 1981, a microestrutura granular mostrou-se bem mais preservada em 0-10 cm, embora algo coalescida e massiva (Figura 1h). Em 40-50 cm de profundidade, percebeu-se tendência à maior massividade, com blocos subangulares pequenos (Figura $1 \mathrm{i}$ ), possivelmente associados às flutuações de umedecimento e secagem em profundidade.

O sítio 4, igualmentereabilitado em 1981, mostrou bolsões com características micropedológicas bem mais preservadas, com mi croagregação bem definida em superfície, com agregados maiores na faixa de $0,2-0,5 \mathrm{~mm}$ e agregados pequenos na faixa de $0,02-$ $0,06 \mathrm{~mm}$, com cores mais avermelhadas, indicando caráter mais oxídico e menos caulinítico dos agregados menores (Figura 1j). Ao lado do plasma denso, notaram-se bolsões com restos orgânicos recentes, lignificados, bem como fragmentos de carvão dispersos (Figura $1 \mathrm{j}$ ), indicando intensa atividade biol ógica atual neste sítio, em comparação aos sítios 1, 2 e 3, anteriores, de mesma idade, o que é atribuído aos maiores teores de C-evoluído (indicativo de atividade biológica no solo) nos macroagregados na profundidade de $0-2,5 \mathrm{~cm}$, que mais seaproxima do LA (dados publicados em Ruivo \& Schaefer, 1998). As características micropedológicas deste solo de $0-10 \mathrm{~cm}$ são as que mais se aproximam da condição de referência, o LA natural, entre os sítios reabilitados em 1981.

Nosítio 10, reabilitado em 1984, nocentro do platô, notou-se grande contraste entre a microestrutura da camada superior com forte mi croagregação (Figura $1 \mathrm{k}$ e Il) eo material subjacente(Figura Im,n), onde se percebeu a dominância da microestrutura massiva, com abundantes fragmentos de laterita bauxítica e quartzosa, sendo envolta por plasma argi loso coeso, que formou estrutura em blocos pela alternância de cicl os de umedecimento e secagem.

No sítio 12, reabilitado em 1987, ocorreu padrão semel hanteao sítio 10, porém com menor massividade na camada inferior $(40-50 \mathrm{~cm})$, sendo os nódul os mais lateríticos e menos concrecionados queos do sítio 10 , evidenciando grande heterogeneidade do material.

$\mathrm{Na}$ figura 1o, está ilustrado um canal biológico comum, preenchido com pelotas fecais, indicando 

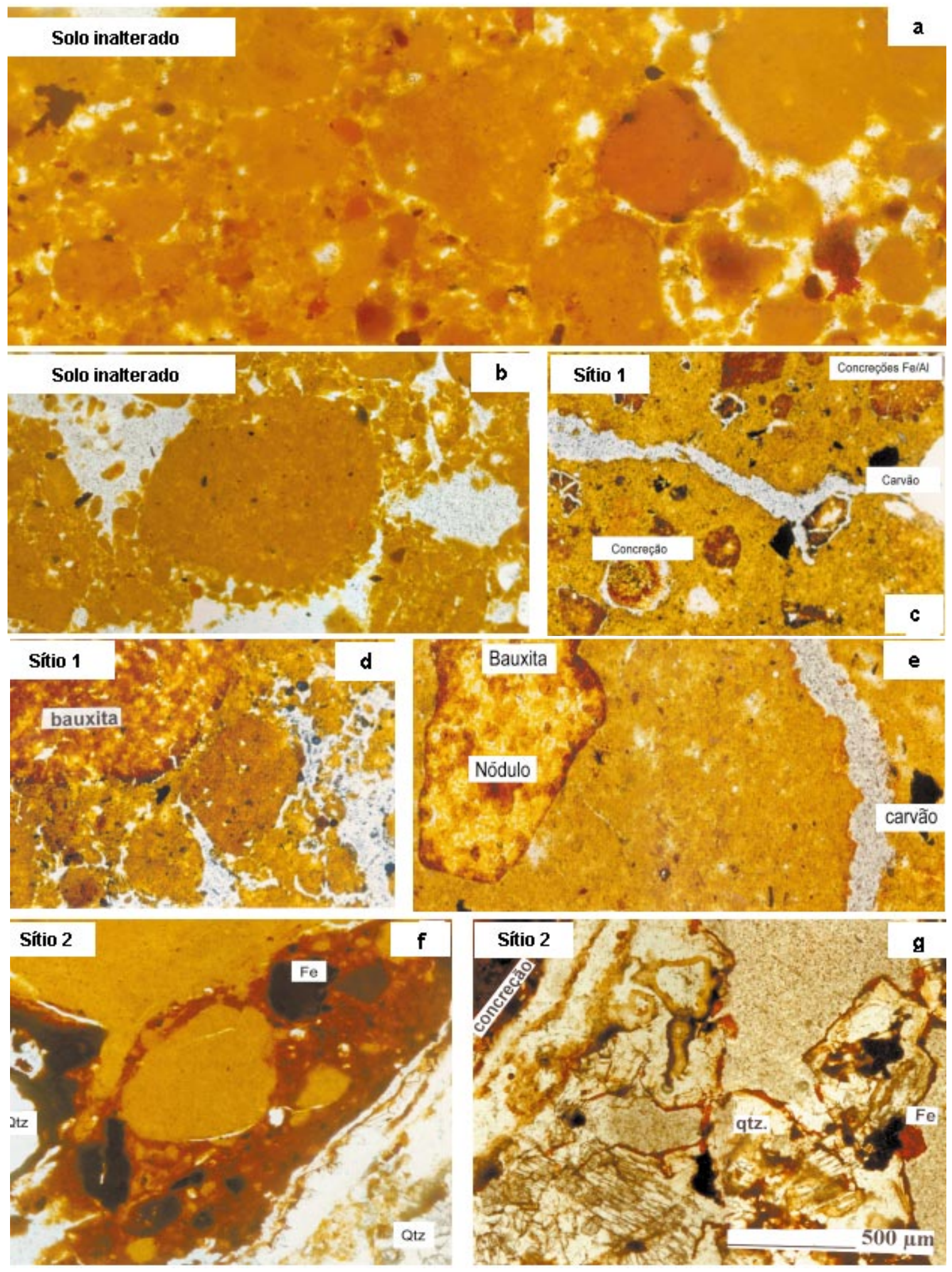

Figura 1. (a) LA: microagregação à profundidade de $10 \mathrm{~cm}$; (b) LA: microagregação à profundidade de $50 \mathrm{~cm}$; (c) e (d) sítio 1: concreçôes bauxíticas, microestrutura massiva e blocos subangulares; (e) migração de Fe em direção à parte do poro; (f) e (g) sítio 2: precipitação de Fe na superfície de antigos microagregados coalescidos e na superfície de grãos de quartzo; (h) sítio 3: microestrutura coalescida e massiva à profundidade de $10 \mathrm{~cm}$; (i) sítio 3: microestrutura massiva à profundidade de $50 \mathrm{~cm}$; (j) sítio 4: microagreagação, restos orgânicos abundantes e fragmentos de carvão dispersos; (k) e (I) sítio 10: microagregação forte na camada superior; $(\mathrm{m})$ e (n) dominância de microestrutura massiva e fragmentos de laterita; (o) canal biológico preenchido por pelotas fecais. 


\section{Figura 1. Continuação}
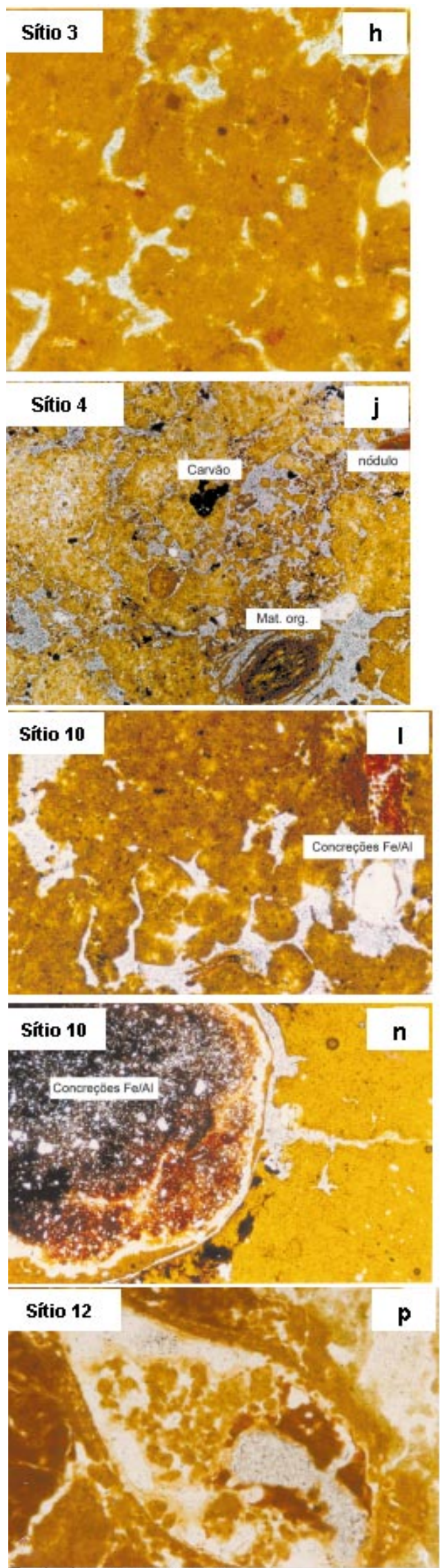
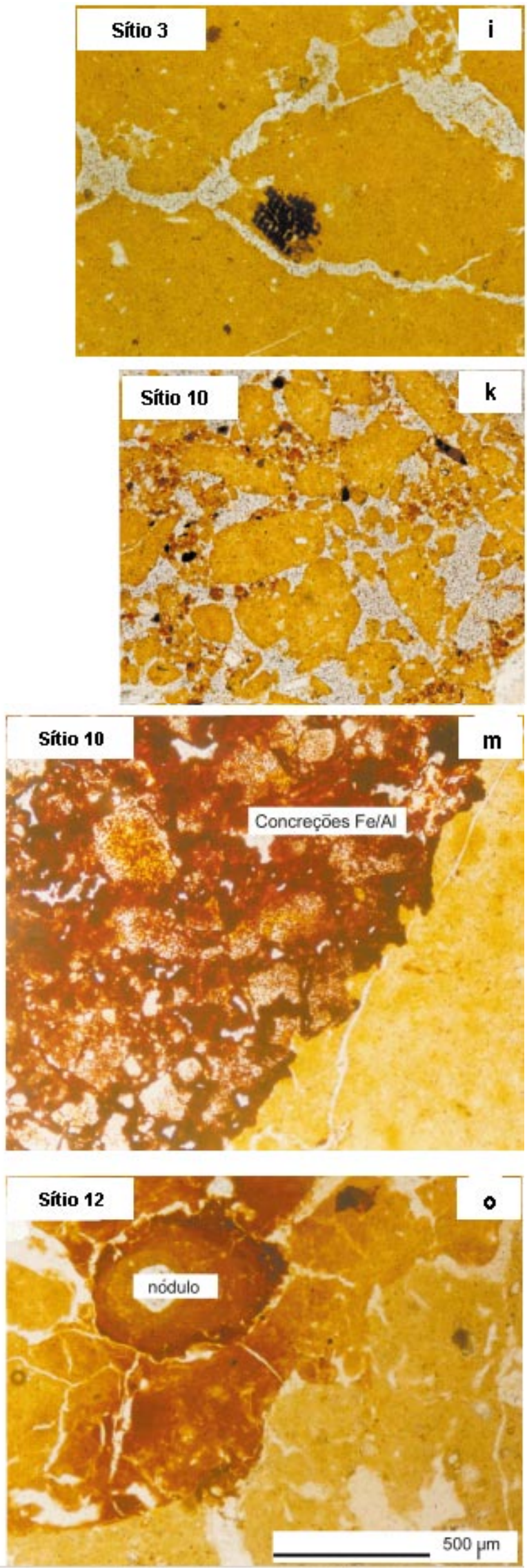
bioturbação ativa desde a reabilitação. Em geral, a atividade biológica, em forma de canais biológicos, microagregados termíticos, pelotas fecais (Schaefer, 2001), restos lignificados e fragmentos de carvão, é mais comum nas camadas superiores, sendo abundante em al guns sítios al terados (sítios 4 e 12), provavel menteem razão da mistura e do incremento da ação biológica após a revegetação e aportes orgânicos dela derivados.

\section{Análises microquímicas em MEV/EDS}

Foram obti dos mapas mi croquímicos eimagens de retroespal hamento eletrônico, por meiode microscópio eletrônico de varredura J EOL 6400 (Figura 2 e
Quadro 2). Em (A), pode-seobservar a microestrutura do horizonte $A(0-10 \mathrm{~cm})$ do LA de referência, com grãos de quartzo e plasma típico de argilominerais 1:1, com nódulos de Fe eAl, dispersos. A microestrutura superficial dos solos do sítio 4, de $0-10 \mathrm{~cm}$, ilustrado em (B), assemel ha-se ao LA de referência, mas ocorre uma mistura de nódul os gibbsíticos (com el evados teores deAl; detal heem D) emacroagregados cauliníticos (teores semel hantes de Al e Si; detalhe em E ) (Quadro 2, análises microquímicas), em meio ao plasma tipicamente caulinítico (Quadro 2). No solo superficial $(0-10 \mathrm{~cm})$ do sítio 10 , onde houve retorno do topsoil, ocorreram abundantes canais biológicos em meio aos microagregados termíticos, evidenciando intensa pedobioturbação.
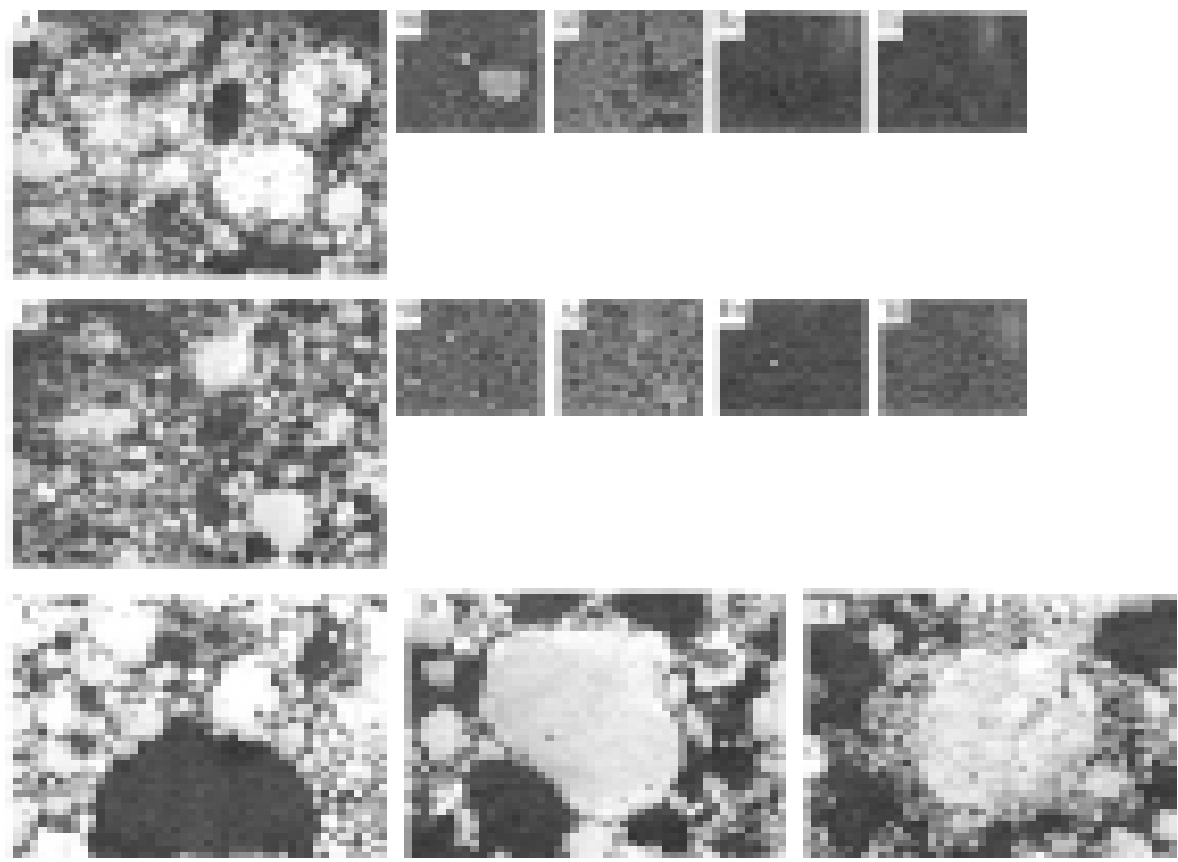

Figura 2. Fotomicrografias em retroespalhamento eletrônico (backscattering) em MEV e respectivos mapas microquímicos de EDS para Si, Al, Fe e Ti, em algumas feições selecionadas em amostras do Latossolo Amarelo de referência (foto A), horizonte A do sítio 4 (fotos B, D e E) e sítio 10 (foto C). Os respectivos dados analíticos de EDS estão reportados no quadro 2.

Quadro 2. Análises químicas quantitativas de elementos selecionados em fei ções pedológicas e no plasma em lâminas de solo superficial, por meio de EDS acoplado ao MEV J EOL 6400

LA referência Plasma microagregado em (A)
Sítio 4 (0-10 cm) Plasma microagregado em (B)
Sítio $4(0-10 \mathrm{~cm})$ Nódulo gibbsítico (D)
Sítio $4(0-10 \mathrm{~cm})$

Agregado caulinítico (E)

\begin{tabular}{lcccc}
\hline & & & & \\
\cline { 2 - 5 } $\mathrm{SiO}_{2}$ & 27,5 & 27,9 & 18,1 & 29,1 \\
$\mathrm{Al}_{2} \mathrm{O}_{3}$ & 24,5 & 26,3 & 40,8 & 26,1 \\
$\mathrm{Fe}_{2} \mathrm{O}_{3}$ & 2,3 & 1,95 & 1,45 & 6,25 \\
$\mathrm{TiO}_{2}$ & 1,8 & 1,7 & 1,1 & 2,3 \\
$\mathrm{CaO}$ & 0,08 & 0,07 & 0,04 & 0,06 \\
$\mathrm{~K} 2 \mathrm{O}$ & 0,05 & 0,07 & 0,04 & 0,04 \\
$\mathrm{P}_{2} \mathrm{O}_{5}$ & 0,07 & 0,06 & 0,06 & 0 \\
\hline
\end{tabular}




\section{CONCLUSÕES}

1. O retorno da matéria orgânica, seja pelo espalhamento dotopsoil do LatossoloAmarelooriginal, seja adicionada pela vegetação que se estabeleceu com a recolonização da biota do solo, acelerou a recuperação microestrutural dos solos alterados.

2. Os sol os alterados, principal mente da borda do platôSaracá, apresentaram grandeheterogeneidade espacial do material de cobertura. A microestrutura desses solos alterados tendeu para maior massividade geral e empacotamento, em relação ao Latossolo Amarelo de referência; em alguns casos, este fato alterou as condições redox do solo, com reprecipitação de Fe.

3. A microestruturação do sol o mostrou-se mais desenvolvida em superfície em todos os sítios alterados, tendo os sítios 4 (1981), 10 (1984) e 12 (1987) apresentado o padrão mais próximo do Latossol o Amarelo de referência.

4. Análises microquímicas em MEV/EDS comprovaram a heterogeneidade mineralógica e estrutural dos solos alterados, com mistura de nódulos gibbsíticos e ferruginosos, agregados cauliníticos e plasma dominado por argilominerais 1:1, sob intensa pedobioturbação.

\section{LITE RATURA CITADA}

DURGIN, P.B. \& CHANEY, J.G. Disperson of kaolinite by dissolved organic matter fron Douglas-fir roots. Can. J. Soil Sci., 64:445-455, 1984.

EMPRESA BRASILEIRA DE PESQUISA AGROPECUÁRIA EMBRAPA. Manual de métodos de análises de solo. Rio de J aneiro, 1997. Não paginado.

FERRAZ,J .B. Diagnóstico do comportamento do reflorestamento realizado na mina Saracá IV (Porto Trombetas - PA) entre 1981 - 1987. Manaus, 1991. Não paginado.

FARIA, J.C. Dinâmica da água, comportamento térmico e selamento de um Podzólico Vermel ho-Amarelo em relação ao controle de plantas invasoras. 1996. 75p. (Tese de Mestrado)

FITZPATRICK,E.A. Soil microscopy and micromorphology. New York, J onh Wiley \& Sons, 1993. 304p.

GOLDBERG, S.; KAPOOR, B.S. \& RHOADES, J.D. Effect of aluminum and iron oxides and organic matter on flocculation and disperson of arid zone soils. Soil Sci., 150:588-593, 1990.

LACERDA, M.P.C.; ANDRADE, H. \& QUÉMÉNEUR, J J.G. Micropedologia ealteração em perfis de sol os com B textural na região de Lavras, Minas Gerais. R. Bras. Ci. Solo, 24:829-841, 2000.

LI, R.S. \& DANIELS, W.L. Nitrogen accumulation and form over time in young mine soils. J. Envirn. Qual., 23:166172, 1994.
MARTINS, P.F.S.; CERRI, C.C.; ANDREUX, F. \& VOLKOFF, B. O solo de um ecossistema natural de floresta localizado na Amazônia oriental. II. fracionamento da matéria orgânica do horizonte A. B. Museu Paraense Emílio Goeldi., Ser. Ci. Terra, 1:79-89, 1989.

NASCIMENTO, D.A. Folha AS.21 - Santarém. II geomorfologia. In: BRASIL/DNPM. Projeto RADAMBRASIL. Folha AS.21- Santarém. geologia, geomorfol ogia, pedologia, veegtação e uso potencial da terra. Rio de J aneiro. DNPM, 1976. p.133-181. (Levantamento de Recursos Naturais, 10)

NUNES, W.A.G.A.; SCHAEFER, C.E.G.R.; KER, J.C. \& FERNANDES FILHO, E.I. Caracterização micropedológica dealguns sol os da zona da mata mineira. R. Bras.Ci. Solo, 24:103-115, 2000.

OLIVEIRA, C.V.; KER, J.C.; DUARTE, M.N.; CURI, N. \& FONTES, L.E.F. Atributos micromorfológicos de solos do Projeto J aíba, norte de Minas Gerais. R. Bras. Ci. Solo, 24:117-128, 2000.

PARROTTA, J.A., KNOWLES, O.H. \& WUNDERLE JR., J.M. Devel opment of floristic diversity in 10-year-old restoration forests on a bauxite mined site in Amazonia. For. Ecol. Manag., 99:21-42, 1997.

PEREIRA, F.S. \& KNOWLES, O.H. Recuperação das áreas mineradas pela Mineração Rio do Norte em Porto Trombetas. In: DNPM. Coletânea de trabalhos técnicos sobre controle ambiental na mineração. Brasília, DNPM, 1985. p.343-358.

PROMOM. Plano Diretor Ambiental de Porto Trombetas, proteção e recuperação do meio ambiente. Rio de J aneiro, 1988. 169p.

RUIVO, M.L.P. \& SCHAEFER, C.E.G.R. Formas e distribuição de carbono em diferentes classes de agregados em sítios recuperados após exploração de bauxita na Amazônia. In: REUNIÃO BRASILEIRA DE MANEJ O E CONSERVAÇÃO DE SOLO E DA ÁGUA, 12, Fortaleza, 1988. Resumos Expandidos 12, Fortaleza, Sociedade Brasileira de Ciência de Solos, 1998. p.392-393.

RUIVO, M.L.P. Caracterização das condições edáficas do Latossol o Amarel o textura muito argilosa após mineração de bauxita em Porto Trombetas-Oriximiná-Pará. Belém, Faculdade de Ciências Agrárias do Pará, 1991. 199p. (Tese de Mestrado)

RUIVO, M.L.P. Vegetação e características do solo como indicadores de reabilitação de áreas mineradas na Amazônia Oriental, Viçosa, Universidade Federal deViçosa, 1998. 101p. (Tese de Doutorado)

SCHROEDER, S.A. Topographic influences on soil water and spring wheat yields on redaimed mineland. J. Environ. Qual., 24:467-471, 1995.

VIANA, C.D.B. Folha SA.21 - Santarém. III - pedologia. In: BRASIL/DNPM. Projeto RADAMBRASIL. Folha AS.21Santarém. geologia, geomorfologia, pedologia, veegtação e uso potencial da terra. Rio deJ aneiro, DNPM, 1976. p.201303. (Levantamento de Recursos Naturais, 10)

VISSER, S.A. \& CAILLIER, M. Observations on the dispersion and aggregation of clays by humic substances: I. dispersive effects of humic acids. Geoderma, 42:331-337, 1988. 
M.L. P.RUIVO et al.

R. Bras. Ci. Solo, 26:759-767, 2002 